\title{
Aproximación al faro como referente histórico-artístico y cultural
}

\author{
Laura Mier Valerón \\ Universidad de Oviedo
}

RESUMEN:

La intención de este artículo es la de realizar un breve recorrido de carácter universal por la trayectoria del faro como referente histórico-artístico y cultural, trascendiendo la mera dimensión física de esta estructura arquitectónica así como su uso a modo de herramienta empleada en el campo de la señalización y de la navegación marítimas. En este sentido, se insistirá en la importancia de este elemento como hito patrimonial de referencia y recurso dinamizador, característico e identitario del paisaje costero en el que se ubica. También se le prestará especial atención al impacto cultural que el faro ha ejercido en ciertos ámbitos como el de la creación artística.

\section{PALABRAS CLAVE:}

Faro, paisaje costero, cultura visual, arte, obra pública

\section{ABSTRACT:}

This paper intends to make a journey through the trajectory of the lighthouse as a cultural reference, transcending the physical dimension of this architectural structure as well as its functionality as a milestone used in maritime signaling and navigation. At this point, the importance of this element will be emphasized as a heritage landmark as well as a dynamic, characteristic and identitary resource of the coastal landscape in which it is located. Likewise, special attention will be paid to the cultural impact that the lighthouse has made in certain areas such as artistic creation.

\section{KEY WORDS:}

Lighthouse, coastal landscape, visual culture, art, public works 
El origen del faro como torre costera de señalización se remonta a una etapa tardía de la Antigüedad, si bien ésta se identifica con una cronología un tanto flexible al no conocerse con certeza el momento exacto de su aparición. Sin embargo, no se vacila a la hora de subrayar la importancia que en el surgimiento y la evolución de esta infraestructura tuvieron dos fenómenos de alcance fundamental. El primero de ellos corresponde a las señales luminosas que desde tierra se hacian mediante la manipulación de los fuegos costeros, unas pequeñas hogueras que eran creadas para indicar a los navegantes sitios seguros donde fondear sus embarcaciones durante la noche -actividad que puede rastrearse en la literatura de la época-. El segundo tiene que ver con la hipótesis que apunta a las torres de vigilancia militares como modelo elegido para albergar unas fuentes lumínicas que, a su vez, podrían potenciar y amplificar su campo de acción. No obstante, a pesar de los avances experimentados por la arqueología subacuática, los estudios que se dedican a desentrañar esta cuestión suelen estar enfocados desde una perspectiva histórico-arqueológica convencional, quedando constreñidos por los múltiples escollos que implican los escasos restos materiales conservados. Es por ello que los distintos especialistas se han afanado en combinar el análisis material con la interpretación de otras fuentes como la numismática, la glíptica, la musivaria, la literatura mitológica y otros documentos clásicos similares $^{1}$. En este sentido, el faro de Alejandría, o la que fuera la primera gran edificación relativa de la que se tiene constancia, sólo ha venido a avivar el halo de misterio que rodea el origen de esta tipología constructiva. Aún así, lo que sí es bien sabido es que su localización geográfica dio lugar al origen etimológico de la palabra empleada para designar estas edificaciones ${ }^{2}$.

Esta casuística impide la constatación de algunos de los rasgos barajados para el funcionamiento y la naturaleza del faro, siendo el caso de la proyección de señales sonoras o diurnas para la guía de las embarcaciones. Dichas hipótesis se prolongan hasta alcanzar uno de los faros más antiguos e importantes de Occidente, el faro de Alejandría, que según Plinio habría sido construido en el siglo III a.C. sobre la isla del mismo nombre. Para más información consúltese Martínez Maganto, Julio, "Faros y luces de señalización en la navegación antigua”, en Cuadernos de Prehistoria y Arqueología, CUPAUAM, n. 17, Madrid, 1990, pp. 67-89.

2 Se tiene constancia de la gran cantidad de obra que se hace eco de este hito paisajístico así como de la hetero-
En consonancia con lo anterior, la historia del faro en España también se retrotrae en el tiempo dada la existencia de longevos ejemplares como la Torre de Hércules en La Coruña (s. I a.C.), el faro de Porto Pí en Palma de Mallorca (s. XIV) y el faro de Camarinal o faro de Cabo de Gracia en Zahara de los Atunes (s. XVI), un antiguo torreón vigía edificado para defender la costa gaditana de los ataques berberiscos ${ }^{3}$. De la misma forma, la situación señalada para el origen de este hito paisajístico también ha favorecido la proliferación de explicaciones de cuño mitológico en nuestro territorio. Al caso, nos vienen a la memoria las distintas leyendas que, entremezcladas con las narraciones históricas y otro tipo de relatos, ilustran la creación de la Torre de Hér-

geneidad de su naturaleza y procedencia. Por mencionar algunos de estos ejemplos diremos que se cuenta con piezas numismáticas y dibujos de época antigua, diversas propuestas técnicas basadas en los textos de cronistas y viajeros, los famosos grabados de Johann Bernhard Fischer von Erlach (1656-1723) así como las distintas imágenes que, a lo largo de este artículo, irán siendo mencionadas. De entre las numerosas reconstrucciones técnicas destacan aquellas que toman el faro de Alejandría como objeto de estudio y de entre las cuales mencionaremos algunas como la de Hermann Thiersch (1874-1939), llevada a cabo a principios del siglo XX y quizás una de las más conocidas. En España también disponemos de la reconstrucción realizada por el profesor arabista Miguel Asín Palacios (1871-1944), quien llegó a cotejar las distintas referencias literarias procedentes de la Antigüedad con los escritos del viajero andalusí Ibn al-Sayj y la información de los geógrafos árabes activos entre los siglos IX y XIV. Asín Palacios, Miguel, "Una descripción nueva del faro de Alejandría”, en Revista Al-Ándalus, vol. II, n. 1, Madrid, 1933, pp. 241-292. Además se pueden citar otras aportaciones recientes como la de Durán FuEnTES, Manuel, "Faros de Alejandría y Brigantium: propuestas de reconstitución formal, estructural y de funcionamiento de la luminaria de la Torre de Hércules de A Coruña", en Actas del Séptimo Congreso Nacional de Historia de la Construcción, Madrid, Instituto de Juan de Herrera, 2011, pp. 339-346.

3 En relación al faro de Caraminal, arquitectura estudiada por el especialista a continuación mencionado, citaremos algunos de los trabajos de referencia de Teodoro Falcón Márquez (Sevilla, 1941), autor de numerosas publicaciones que han prestado especial atención a los faros de la costa andaluza. FAlcón MÁrquez, Teodoro, "La arquitectura del mar. Nuevas tipologías de faros y nuevos materiales", en Arquitectura y ciudad en España de 1845 a 1898. Actas de las I Jornadas de Arquitectura Histórica y Urbanismo, Servicio de $\mathrm{Pu}-$ blicaciones de la Universidad de Cádiz, 2000, pp. 157160. FAlcón Márquez, Teodoro, “Arquitectura del mar. El universo de los faros andaluces. Costa Atlántica”, en Revista Ph: Boletín del Instituto Andaluz de Patrimonio Histórico, n. 53, Sevilla, 2005, pp. 45-54. 
cules, la torre-faro localizada en La Coruña y declarada en el año 2009 Patrimonio de la Humanidad por la Unesco ${ }^{4}$. Al respecto queda registrada una leyenda popular que cuenta la llegada de Hércules a las costas gallegas para enterrar la cabeza del gigante Gerión, justo en el lugar que actualmente ocupa la torre, tras haber sido este vencido y muerto en combate por el hijo de Zeus. En ejemplos como este se aprecia el rol que estos relatos desempeñan como catalizadores de fórmulas que funden ficción y realidad para legitimar cierto linaje, quedando aquí establecida la relación entre el legado tartésico-fenicio de Gerión y el romano propio de Hércules. Además, estos mecanismos perduran en el tiempo como herramienta ideológica con la que forjar aquella tradición que ayude a consolidar una historia y conciencia identitaria. Tanto es así que el propio rey Alfonso X el Sabio (1221-1284) se hace eco del hecho anteriormente descrito, recogiéndolo en su Crónica General de España para poder ilustrar la fundación de la ciudad de La Coruña ${ }^{5}$.

Otra de las fábulas más famosas nos llega a través de la interpretación de un pasaje recogi-

\footnotetext{
Al margen de la propaganda mítica se sabe que la torre-faro de Hércules fue construida en el siglo I a.C. debido a la situación experimentada tras la proliferación de las relaciones comerciales y las mejoras de la red viaria y del tráfico marítimo, consecuencias directas de la Paz Augusta. Este fenómeno favoreció la romanización del norte de la Península Ibérica y permitió a Roma avanzar en la conquista de Britania, requiriendo para ello de un mayor número de enclaves en el noroeste peninsular. La necesidad de implantar un faro en la zona de Fisterra era urgente ante la inexistencia de una infraestructura que pudiese guiar las embarcaciones hacia el Canal de la Mancha, una zona peligrosa por sus aguas bravías. Para más información véase Fernández OchoA, Carmen y Morillo Cerdán, Ángel, "La romanización atlántica: modelo o modelos de implantación romana en el noroeste peninsular", en Portvgalia, Nova Série, vol. 36, Porto, DCTP-FLUP, 2015, pp. 183-197 y http://ciav. torredeherculesacoruna.com/el-faro-en-el-tiempo/ [último acceso: 20-XI-2018, 16:54].

5 "E mando en aquel logar fazer una torre muy grande, e fizo meter la cabeza de Gerion en el cimiento, e mando poblar y una gran cibdat, e fazie escreuir los nombres de los omnes e de mugeres que viniesen poblar y el primer poblador que uino fue una muger que auia nombre de Cruna, e por essol poso assi nombre a la cibdat. E una gran partida de la gente que el traye fueron de Galacia, e mandolos poblar allí; e por esso fue llamada aquella tierra Galizia”. MENÉndEZ PIDAL, Ramón, Primera Crónica General: Estoria de España que mandó componer Alfonso el Sabio y se continuaba bajo Sancho IV en 1289, vol. I, Bailly-Bailliere é hijos, Madrid, 1906, pp. 9-10.
}

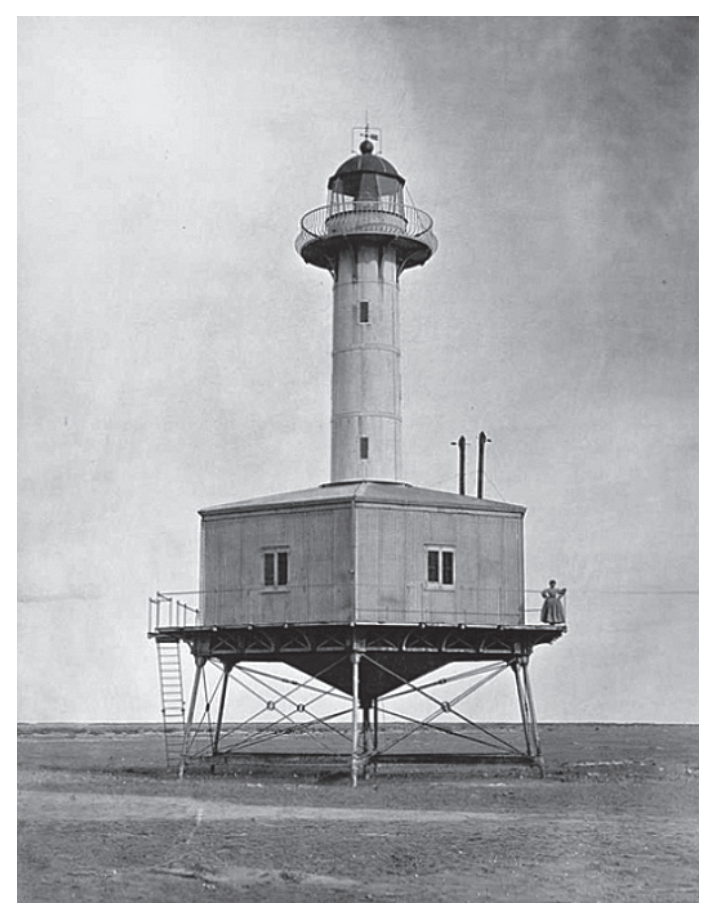

Fig. 1 Faro de la Punta de la Baña, Tarragona (1867). Fotografía de Jean Laurent. Procedente de los fondos de la Biblioteca Nacional de España.

do en el Libro de las Invasiones, manuscrito fechado en el siglo XII, en donde monjes galeses e irlandeses narran las aventuras que corrieron otros héroes legendarios que nada tienen que ver con Hércules ${ }^{6}$. Dicen que fue el rey Breogán quien fundó la ciudad de Brigantia y con ella una gran torre que sería bautizada como la Torre de Breogán. Así, esta fuente denota una voluntad similar a la de la leyenda anterior si bien aquí se sustituyen unos lazos por otros al entrecruzarse celtismo irlandés y celtismo ga$\operatorname{llego}^{7}$. Es en estos contextos, indicadores del vínculo existente entre el origen tipológico del faro como torre de vigilancia y su empleo como marca territorial a la cual asociar distintos linajes e historias, donde se aprecia el destacado valor conferido a dichas construcciones. Sin embargo, no debe de extrañarnos puesto que son infraestructuras heredadas que poseen un importante atractivo histórico y geopolítico a

Para más información consúltese Leabhar Ghabhála ó Libro de las Invasiones en la siguiente edición: AUTOR ANónImo, Leabhar Ghabhála (Libro de las Invasiones), Akal, Madrid, 2010.

7 Pereira GonzÁlez, Fernando, “Lorenzo Hervás o celtismo galego e a lenda de Breogán”, en Gallaecia: revista de arqueología e antigüidade, n. 32, Santiago de Compostela, 2013, pp. 169-190. 


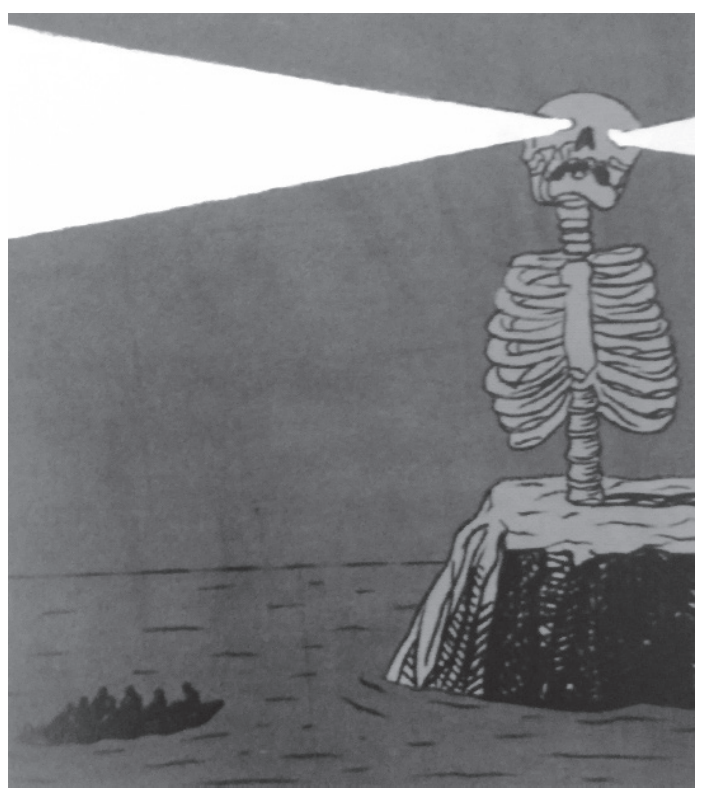

Fig. 2 Pateras de El Roto (Andrés Rábago). Obra localizada en el Centro de Arte Faro de Cabo Mayor de Santander.

la par que se erigen como baluartes en zonas estratégicas que separan la tierra del mar y la civilización de la naturaleza.

Este cúmulo de circunstancias explica el papel que han venido cumpliendo los faros como elementos activos en la construcción territorial de las distintas identidades costeras. De la misma manera no hay nada más representativo del poder local que un bastión cuya proyección visual alcanza toda la línea de costa, dominando el paisaje, pudiendo ver y ser visto desde la distancia mediante una presencia omnisciente, hasta cierto, punto similar a la del panóptico de Bentham -ya que su sola existencia modela y condiciona la actividad humana circundante-. Aunque el faro posea una funcionalidad orientativa no es menos cierto que podría ser interpretado en términos prescriptivos, a semejanza de la presencia de instituciones como el Estado o la Iglesia, puesto que, más allá del dominio visual de tipo proyectivo, su ubicación elevada y estratégica asegura un exhaustivo control visual y conductual. Igualmente, esta connotación podría prolongarse a la figura del farero, el cual podría ser pensado como un centinela, guardia o vigía que protege un lugar desde su puesto de observación, preservando el correcto funcionamiento de las normas establecidas. Sin embargo, los faros y los fareros no suelen ser identificados como instrumentos coercitivos o negativamente asociados al control social y territorial sino todo lo contrario.
Si se consultan las definiciones contempladas para la voz "faro" se encuentran acepciones mayoritariamente positivas, aunque tampoco faltan aquellas que se refieren a este como fuente de soledad o de locura. La segunda acepción contemplada por la RAE, aquella que lo caracteriza como "farol con potente reverbero", llega a evocar el recuerdo de las linternas o faroles que fueron empleados en ceremonias y ritos templarios a lo largo de distintas culturas, civilizaciones y cronologías. Se pueden mencionar ejemplos como los faroles simbólicos utilizados en Japón hasta la época Muromachi (1333-1576), momento en el que comienzan a perder esta significación como símbolo de iluminación y claridad del espíritu pasando a cumplir una función más bien ornamental y estética al emplearse en el arte de los jardines y en la ceremonia del té. También se encuentran otros casos en la tradición occidental relacionados con las linternas de los muertos, unos fuegos que ardían durante toda la noche cerca del cadáver del difunto o delante de su casa para reflejar la inmortalidad de su alma allende el cuerpo perecedero. De la misma manera, hallamos el empleo lumínico que materializa un concepto tan abstracto como el de Cristo luz del mundo y guía de la humanidad hacia la inmortalidad, la trascendencia y la vida celestial ${ }^{8}$.

Volviendo a las definiciones disponibles en la RAE, la cuarta acepción nos indica que "faro" también puede ser "aquello que da luz a un asunto, lo que sirve de guía a la inteligencia o a la conducta", significado vinculado a la asociación establecida entre luz ${ }^{9}$ y razón y sombra

\footnotetext{
Para ampliar esta información acudir a la voz "linterna" o "farol" en Chevalier, Jean y GHeErbrant, Alain, Diccionario de los símbolos, Herder, Barcelona, 2003, p. 650.

9 En distintas leyendas, narraciones o relatos mitológicos y religiosos la luz representa algún tipo de ayuda espiritual que permite a su protagonista vencer los distintos infortunios y las adversidades que se interponen en su camino. De la misma forma, nos encontramos con diversas "luces" que no siempre provienen de una fuente exógena que "ilumina" a dicho protagonista, siendo el resultado de la lucha o iluminación interior. También contamos con ejemplos en los que ambas luces, de procedencia exógena y endógena, coexisten en una misma historia. A tal efecto, mencionaremos la hazaña de Teseo por escapar del minotauro en el laberinto y de cómo la leyenda cuenta que el protagonista no sólo pudo regresar gracias a su perseverancia sino también por el ovillo de Ariadna y la luz que emitía la corona de ésta. Chevalier, Jean y Gheerbrant, Alain, op. cit., Diccionario..., pp. 663-664.
} 
y sinrazón ${ }^{10}$. Dejando de lado algunas de las implicaciones que este concepto engloba, como la del conocimiento o la revelación adquiridos a través del sentido de la vista ${ }^{11}$, aludiremos al impacto que en nuestra herencia cultural ha tenido la metodología cognoscitiva del movimiento ilustrado y a la significación general que poseen buena parte de las metáforas visuales sobre el faro, en las cuales puede ser rastreado el paralelismo entre luz y salvación o esperanza pero también entre sombra y soledad.

Son diversos los casos en los que se emplea la luz del faro como recurso expresivo. En ocasiones, estos usos se vinculan a una intención simbólica o metafórica, siendo aprovechada la dimensión material del faro como atributo iconográfico inteligible de la significación o evocación conceptual a la que se pretende aludir. Otras veces esta tipología edilicia se utiliza como lugar asociado a la ambientación emocional y a la creación artística y como emplazamiento en el que experimentar nociones como la relatividad espacio-temporal. Podemos mencionar ejemplos literarios como el relato inconcluso El Faro (1849) de Edgar Allan Poe, los poemas "Los Faros" (Las Flores del Mal, 1861) de Charles Baudelaire, la novela Al Faro (1927) de Virginia Woolf y el poema "Soliloquio del farero" (Invocaciones, 1934-1935) de Luis Cernuda. Sin embargo, las proyecciones de estas luces son distintas puesto que, mientras en la obra de Poe se valora positivamente la soledad y el tiempo libre del farero, algo de lo que su protagonista pretende beneficiarse para escribir un libro, el poema de Cernuda trata con resignación la soledad de este trabajo, aún subrayando el poder ejercido por el farero desde

10 Para las acepciones de la RAE consúltese la web http:// dle.rae.es/srv/search? $\mathrm{m}=30 \mathrm{Atw}=$ faro [último acceso: 20-XI-2018, 18:55].

11 Son muchas las referencias que asocian conocimiento y visión, generalmente adquirido aquel a través de la lectura, si bien este sentido también aparece referenciado como superficial y engañoso. No obstante, en relación a la primera caracterización Cicerón decía que "el más agudo de nuestros sentidos es de la vista" puesto que cuando podemos ver un texto lo recordamos mejor que cuando simplemente lo oímos. Cicerón, De Oratore, ed. E. W. Sutton y H. Rackham, Cambridge y Londres, vol. I, 1976, p. 87. San Agustín también alabó los ojos, si bien más tarde acabó por condenarlos, al ser punto de entrada del mundo. SAn Agustín, Confesiones, Madrid, Tecnos, 2012. Santo Tomás de Aquino dijo de la vista que era el más poderoso de los sentidos puesto que a través suyo adquirimos conocimientos. RoBles CARCEDo, Laureano, Tomás de Aquino, Salamanca, Ediciones Universidad de Salamanca, 1992. su puesto. Por el contrario, Baudelaire se aleja completamente de los anteriores para realizar una crítica en clave poética de la trayectoria artística de Rubens, Miguel Ángel o Goya en relación a su liderazgo profesional, estableciendo un paralelismo entre proyección artística y proyección lumínica mediante el título de la obra. A su vez, la novela de cuño autobiográfico escrita por Virginia Woolf aprovecha la ambientación que el faro le brinda para ahondar en la introspección psicológica y la manipulación de la percepción espacial, quedando la trama reducida a un papel secundario ${ }^{12}$.

En términos de creación literaria también se conservan otras obras que tratan el faro desde múltiples perspectivas, siendo el poema "Al faro de Nueva York. La Libertad guiando al mundo" de Melchor de Palau y Catalá (18421910) un buen ejemplo de ello. Melchor de Palau y Catalá ejerció como poeta pero también como ingeniero de caminos, canales y puertos, siendo un buen conocedor del ámbito de las obras públicas y de las construcciones fareras, llegando a aunar en su hacer la pasión que sentía por la poesía lírica y aquella que le profesaba al progreso técnico. Asimismo, el poema en cuestión no es más que un canto metafórico a la neoyorkina Estatua de la Libertad ${ }^{13}$ que recoge aquellos paralelismos establecidos entre el faro y la torre y el farero y el centinela así como la idea del faro como hito paisajístico que arroja luz sobre los navegantes y la humanidad -no sin desdeñar algunos de los aspectos negativos de esta luz-:

Por otra parte, de entre las labores literarias de Melchor de Palau y Catalá se

12 En esta novela aparecen ligadas distintas artes entre si y también pueden rastrearse referencias a la trabazón existente entre los escollos propios del proceso creativo y los correspondientes al drama familiar. Todas estas cuestiones toman forma en la figura de la artista Lily Briscoe. Woolf, Virginia, To the Lighthouse, Hertfordshire, Wordsworth classics, 1994.

13 La Estatua de la Libertad quedó inaugurada por el presidente Cleveland el 28 de octubre de 1886. Se trata de uno de los faros más monumentales que se conservan y su función es la de controlar las entradas y salidas del puerto de Nueva York desde la isla de Bedloe. Fue donada por Francia a los Estados Unidos como recuerdo de la alianza que ambos países habían establecido en la guerra de la Independencia. AMERICAN COMMITTEE OF THE STATUE OF LIBERTY, Inauguration of the Statue of Liberty Enlightening the World: By the President of the United States, on Bedlow's Island, New York, Thursday, October 28, 1886, ed. by D. Appleton, Cambridge (Massachusetts), Harvard University, 1887. 
suele destacar la traducción al castellano en 1878 de La Atlántida de Jacinto Vergader (1845-1902), un sacerdote y poeta barcelonés cuya obra está escrita en catalán. La Atlántida nos trae a la memoria la mítica isla mencionada por Platón en su Timeo y Critias, que no es otra que aquella que se situaba más allá de las columnas de Hércules, por lo que el propio texto de Verdaguer invocaría de nuevo la historia de Gerión y de Hércules como ya lo había hecho Alfonso X el Sabio para describirnos el origen de la torre-faro de La Coruña ${ }^{14}$. De la misma forma, Melchor de Palau y Catalá también nos sirve como paradigma mediante el cual ejemplificar la intensa relación que arte e ingeniería han mantenido desde antaño así como las ingerencias que una ha tenido en los asuntos de la otra y viceversa ${ }^{15}$. Destacaremos aquí la figura de otro ingeniero de caminos, canales y puertos cuyas reflexiones en torno a la belleza, la estética y la funcionalidad de la obra pública han ejercido una importante repercusión en dicho estado de la cuestión. Se trata del madrileño José Antonio Fernández Ordóñez (1933-2000) quien, desde la Escuela Técnica Superior de Caminos, Canales y Puertos de Madrid, desde la propia Acade-

14 Jacinto Verdaguer fue un autor clave en el fenómeno de la Renaixença catalana, por lo que su obra nos permite una vez más presentar al faro como un elemento de dinamización cultural que ha jugado un importante papel en la consolidación de la identidad y la conciencia territoriales. Para más información véanse algunas de sus obras en http://bdh.bne.es/bnesearch/ Search.do? numfields $=1$ \& field $1=$ autor\&tield 1 val $=\%$ 22Verdaguer $\% 2 c+$ Jacint $\% 22$ tffield $10 p=$ AND\&texac$\mathrm{t}=$ on $\mathrm{Atadvanced}=$ trueEtlanguage $=\mathrm{esEn}$ [último acceso: 10-XII-2018, 14:35]. También https://cvc.cervantes.es/ actcult/verdaguer/obra/obra_02.htm [último acceso: 10-XII-2018, 14:37].

15 En este tipo de diálogos encontramos diversas imágenes artísticas que, plasmando un mismo motivo en distintos momentos, nos permiten percibir diferentes fases o estadios de la construcción de infraestructuras. Como ejemplo, el puente de la localidad de Walton fue recogido por Canaletto (1697-1768) durante una estancia en Inglaterra en la obra El Viejo Puente de Walton (1754). Más tarde ve la luz la versión de John Constable, traduciendo el aspecto definitivo de la estructura. Aquí desaparecen las cimbras que reflejaba el veneciano en favor de una obra de fábrica terminada. Para más información consúltese también VÁzQUEZ DE LA Cueva, Ana, "Ingeniería y pintura", en Revista Ingeniería y Territorio, n. 78, Colegio de Ingenieros de Caminos, Canales y Puertos, Madrid, 2007, pp. 48-59. mia de San Fernando o a través de manifiestos como "El pensamiento estético de los ingenieros. Funcionalidad y belleza" (1990), ejerció una labor pionera en términos de concienciación, defensa y protección patrimonial así como de reflexión estética en torno a la obra pública ${ }^{16}$.

Retomando la trayectoria histórica del faro se puede afirmar que, en términos generales, es en la Edad Moderna cuando comienzan a hacerse efectivos los proyectos de iluminación costera. Desde el siglo XVIII, una centuria que ve crecer exponencialmente el comercio marítimo gracias a las unificaciones nacionales, empiezan a ser insuficientes las luces de re-

16 José A. Fernández Ordóñez (Madrid, 1933-2000). Vocal del Real Patronato del Museo del Prado, nombrado en 1993. Fue presidente del mismo desde noviembre de ese mismo año hasta su fallecimiento en 2000. Doctor Ingeniero de Caminos, Canales y Puertos. De 1974 a 1979 fue presidente del Colegio Nacional de Ingenieros de Caminos, Canales y Puertos, colegiado de honor en 1980. A partir de 1981 fue catedrático de historia y estética de la ingeniería en la Universidad Politécnica de Madrid. Desde esta cátedra proclama la necesidad de la enseñanza de la historia de la ingeniería en la formación de los ingenieros como soporte a la realización de sus proyectos. Muy preocupado por la defensa del patrimonio, y en concreto por el de las obras públicas, realizó inventarios y catálogos de este patrimonio cultural tan poco valorado, llevando a cabo rehabilitaciones de obras de ingeniería. En 1988 fue elegido académico de número de la Real Academia de Bellas Artes de San Fernando y en 1994, académico de número de la Real Academia de la Ingeniería de España. Doctor Honoris Causa por la Universidad de Extremadura. Fue condecorado con la gran cruz de la orden civil de Alfonso X el Sabio y colaboró con el escultor Eduardo Chillida en algunas de sus obras. Entre sus numerosísimos proyectos podemos citar el Museo de Escultura al Aire Libre del paseo de la Castellana de Madrid (1968); la rehabilitación de puentes califales, romanos, del siglo XVIII y del siglo XIX (1976-1988); el Nou Pont del Diable sobre el río Llobregat en Martorell (1970); el puente del Milenario sobre el río Ebro en Tortosa (1978); el puente del Centenario sobre la dársena del río Guadalquivir en Sevilla (1986); la pasarela sobre la ría de Bilbao frente al Museo Guggenheim (1996); o el puente Infante Don Henrique sobre el río Duero en Oporto (1998). Publicó numerosas obras sobre ingeniería y protección del patrimonio y fue galardonado con la medalla de oro del concurso internacional para la Exposición Universal de 1992 en Sevilla. Para más información sobre su obra véase FERNÁNDEZ ORDóÑEZ, José A., "Funcionalidad y belleza: el dilema de los ingenieros", en Revista de Economía, n. 14, Madrid, 1992, pp. 107-113 ó FERnÁNDEZ ORdóÑEZ, José A., "El pensamiento estético de los ingenieros. Funcionalidad y belleza”, en Arquitectura española contemporánea: documentos, escritos, testimonios inéditos, Universidad Autónoma de Madrid, Madrid, 2002, pp. 680-684. 


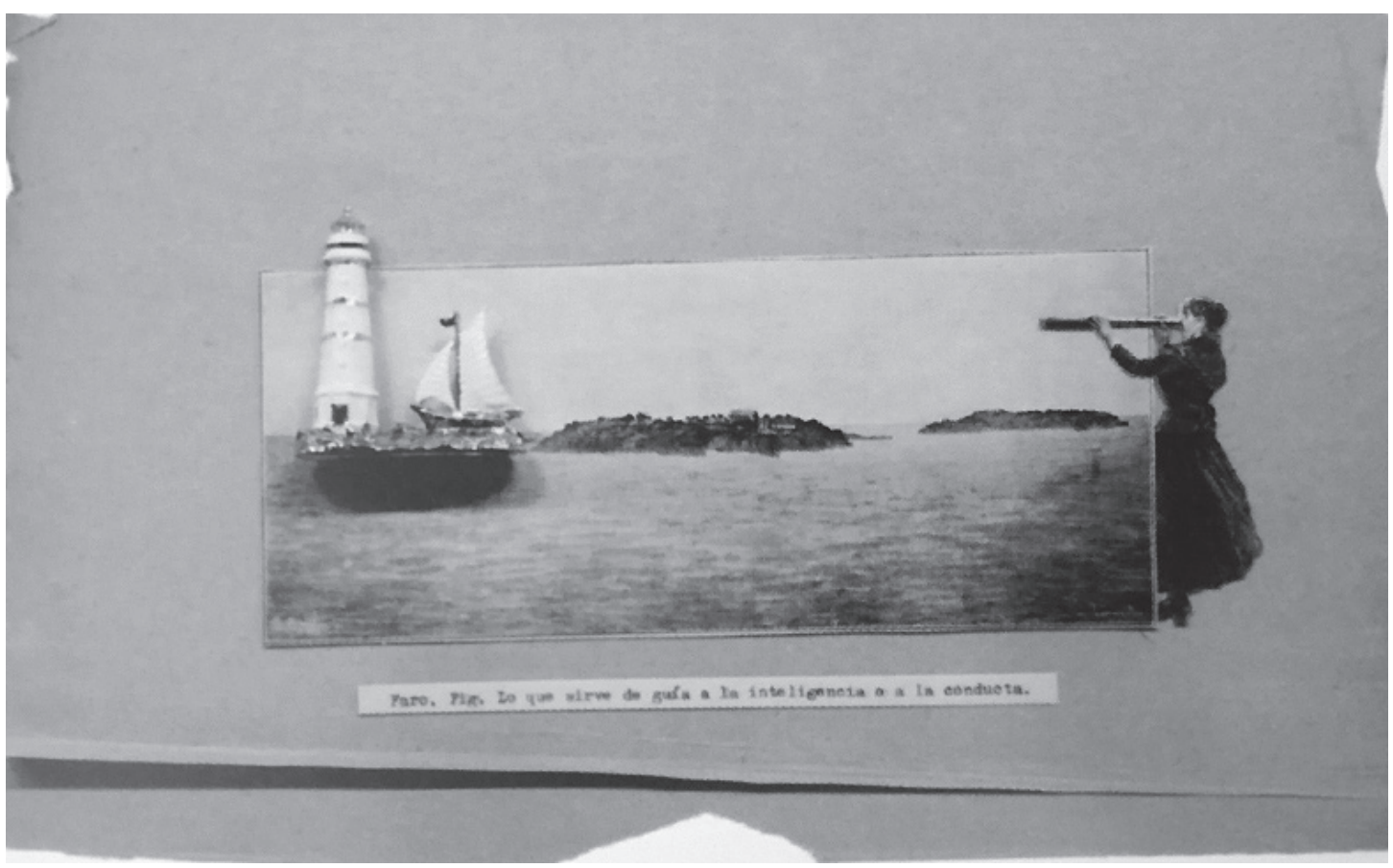

Fig. 3 Faro. Fig. Lo que sirve a la inteligencia o a la conducta (2004) de Sara Huete. Técnica mixta. Obra localizada en el Centro de Arte Faro de Cabo Mayor de Santander.

calada con las que se contaba en los puertos, surgiendo la necesidad de crear una serie de planes para el correcto alumbramiento costero y para la señalización de las barreras y los accidentes. No obstante, España sufrió cierto retraso en la actualización de este tipo de obras públicas puesto que no fue hasta época de Isabel II (1830-1904) cuando comenzaron a ponerse en práctica aquellas políticas suficientes al respecto. Durante los años de su reinado (1843-1870) tuvo lugar un relevante acontecimiento en esta relación arte-ingeniería, el cual quedó registrado en las crónicas y en los documentos gráficos que se hicieron eco de las actividades desarrolladas por el comité español de la Exposición Universal de 1867 en París. A tal efecto, el pabellón de España contó con una exposición de fotografías y maquetas que recreaban las distintas tipologías de obra pública dispuestas a lo largo y ancho de nuestra geografía. Este conjunto disponía de veinte vistas fotográficas y otras tantas maquetas y modelos tridimensionales de nuestros faros, a su vez muestras del elocuente progreso técnico alcanzado durante el reinado de Isabel $\mathrm{II}^{17}$. Aquí figuraban los más importantes fa-

17 Véase Aguilar Civera, Inmaculada, "La mirada fotográfica de la Ingeniería Civil”, en Revista Ingeniería ros construidos gracias a la implantación del "Plan General para el Alumbrado Marítimo de las Costas Españolas” de 1847, siendo el caso de los imponentes faros de hierro de Lucio del Valle (1815-1874), uno de los más destacados arquitectos e ingenieros de caminos, canales y puertos que ha tenido el siglo XIX español y también conocido proyector y director de obras públicas como el sistema de abastecimiento de aguas de Madrid o Canal de Isabel II y el ensanche de la Puerta del Sol ${ }^{18}$. También en la segunda mitad del siglo XIX Jean Laurent (1816-1886) lleva a cabo un compendio fotográfico de los faros españoles, el cual se recoge y analiza exhaustivamente en la publicación Obra Pública en España. Fotografías de J. Laurent, 1858-1870 19

No es casualidad que desde mediados del siglo XIX comiencen a multiplicarse las repre-

y Territorio n. 78, Colegio de Ingenieros de Caminos, Canales y Puertos, Madrid, 2007, pp. 82-93.

18 NAVAscués Palacio, Pedro, "El ingeniero y arquitecto Lucio del Valle”, en Ingenieros arquitectos, Fundación Juanelo Turriano, Madrid, 2015, pp. 95-106.

19 En esta publicación colectiva queda recogido un capítulo dedicado a la fotografía de faros de Jean Laurent. NicolÁs GómeZ, Dora, “Los Faros”, en Obra Pública en España. Fotografías de J. Laurent, 1858-1870, Servicio de Ediciones de la Universidad de Castilla La Mancha, Ciudad Real, 2003, pp. 51-60. 
sentaciones de los faros españoles, ya que por aquel entonces estas construcciones se vieron impulsadas por el "Plan general para el Alumbrado Marítimo de las Costas Españolas”. Gracias al mismo pudo Asturias contar con el faro del Cabo Peñas, el más antiguo que se conserva en nuestra región y que por desgracia no pudo empezar a edificarse hasta el año 1852. Consecuentemente, debido al rápido desarrollo que adquirió el servicio de faros tras la implantación del plan, se formó un Cuerpo de Torreros de Faros mediante una Real Orden del 21 de mayo de 1851. La presencia de una corporación de especialistas, casi colegiados, que operase con capacidades en este ámbito se hizo cada vez más necesaria y urgente por lo que, desde mediados de siglo, este fenómeno fue adquiriendo una mayor complejidad para terminar dando lugar a la creación de las Escuelas Especiales Teórico-Prácticas de Faros, aprobadas mediante otra Real Orden del 21 de mayo de $1851^{20}$. Finalmente, la denominación propia del Cuerpo de Torreros se vio sustituida en 1939 por la de Técnicos Mecánicos de Señales Marítimas, ofreciéndonos estos datos información de importancia sobre la evolución de los faros, de sus gestores y de la cualificación necesaria para el correcto funcionamiento de estas actividades $^{21}$.

Igualmente, el impacto del faro sobre la producción artística como hito paisajístico se mantiene en el tiempo. Y como muestra de este fenómeno traeremos a la memoria una serie de imágenes que, de una $u$ otra forma, recogen o ilustran algunos de sus rasgos más característicos. Mencionaremos ahora diversas obras que forman parte de los fondos de la colección Sanz-Villar, integrada por más de doscientas piezas de distinta autoría y una compilación de

20 "Reglamento para la organización y servicio de los torreros de faros", en Gaceta de Madrid, Madrid, n. 6248, 22-VIII-1851. Véase el documento digitalizado en https://www.boe.es/datos/pdfs/BOE//1851/6248/A0000100002.pdf [último acceso: 22-XI-2018, 12:06].

${ }^{21}$ Consúltese el BOE n. 192 del 11-VII-1939. Véase el documento digitalizado en http://bibliotecavirtualdefensa.es/BVMDefensa/i18n/catalogo_imagenes/grupo.cmd?path=16971[último acceso: 22-XI-2018, 12:29]. Para futuros arreglos sobre la legislación y las disposiciones que afectan a este colectivo véanse otros decretos como aquel de noviembre de 1956 por el que se aprueba el "Reglamento Orgánico del Cuerpo técnico-mecánico de señales marítimas" en BOE n. 346 del 11-II-1956. Véase el documento digitalizado en https://www.boe.es/ datos/pdfs/BOE//1956/346/A07788-07797.pdf [último acceso: 22-XI-2018, 12:10]. casi mil obras de soporte papel -dibujos, acuarelas, grafitos, etc.- realizadas por el artista santanderino Eduardo Sanz (1928-2013). Estas imágenes se conservan en la Sala Cabo Mayor, un espacio coherentemente articulado en una antigua casa de fareros que fue construida en 1839 en la zona de Cabo Mayor en Santander. En este sentido, contingente y contenido quedan perfectamente articulados en torno al faro como protagonista y como objeto de atenciones $\mathrm{y}$ representaciones que han motivado la consolidación de una cultura visual específica. De entre las más de doscientas imágenes de gran y mediano formato que antes mencionábamos encontramos piezas de Isabel Villar (Faro de Villano, 1981), Sergio Sanz Villar (El bicho de Muriel, 1988), Alfredo Alcaín (Bodegón del faro de Guetaria, 1978), Xavier Valls (Faro de Llobregat, 2006), Ángel de la Hoz (Suances, 1989), El Roto (Pateras), Carlos García Alix (Faro de Finisterre, 2003), Antonio Rojas (Faro de Tarifa, 1988), Guillermo Pérez Villalta (Los Transportadores de Luz, 2002), Luís Sáez (El Faro, 1984), José Caballero (El Faro, 1952), Eduardo Úrculo (Faro y desnudo, 1980), Sara Huete (Faro. Fig. Lo que sirve a la inteligencia o a la conducta, 2004), Ricardo Toja (La fuente de Isabel Villar, 1996), Ángel Mateo Charris (El país de los faros, 1996), Eduardo Arroyo (Sin titulo, 1985) o Juan Ballesta (Sin título, 2003) ${ }^{22}$.

También nos encontramos con distintas vistas de los faros de nuestra geografía litoral realizadas por el propio Eduardo Sanz ${ }^{23}$, quien en 1979 comenzó a elaborar un catálogo ilustrado de los faros de nuestras $\operatorname{costas}^{24}$. Se debe subrayar cómo la obra de este artista no podría ser entendida a expensas de una arquitectura a la que ha profesado verdadera devoción y de la que destaca una serie de valores magnéticos a su sentir, como la omnisciencia de sus seña-

\footnotetext{
22 Calvo Serraller, Francisco, Sanz, Eduardo y Sazatornil Ruz, Luis, Centro de Arte Faro Cabo Mayor. Colección Sanz-Villar, Autoridad Portuaria de Santander, Santander, 2006, pp. 59-84.

23 SAnz, Eduardo, Faros. La Colección de Eduardo Sanz, Círculo de Bellas Artes y Asociación de Ingenieros de Caminos, Canales y Puertos, Madrid, 2002.

24 En 1975 Eduardo Sanz ya había comenzado a realizar una serie de representaciones sobre signos y señales marítimas conocidas como "Cartas de amar", dedicándose también a la fabricación de barcos a escala entre 1978 y 1980. Sin embargo, las pinturas de temática farera y marina no aparecen de forma sistemática en su producción hasta el citado año de 1979, prologándose dicha tendencia hasta el final de sus días. SANz, Eduardo, Faros. La Colección de Eduardo Sanz ..., op. cit.
} 


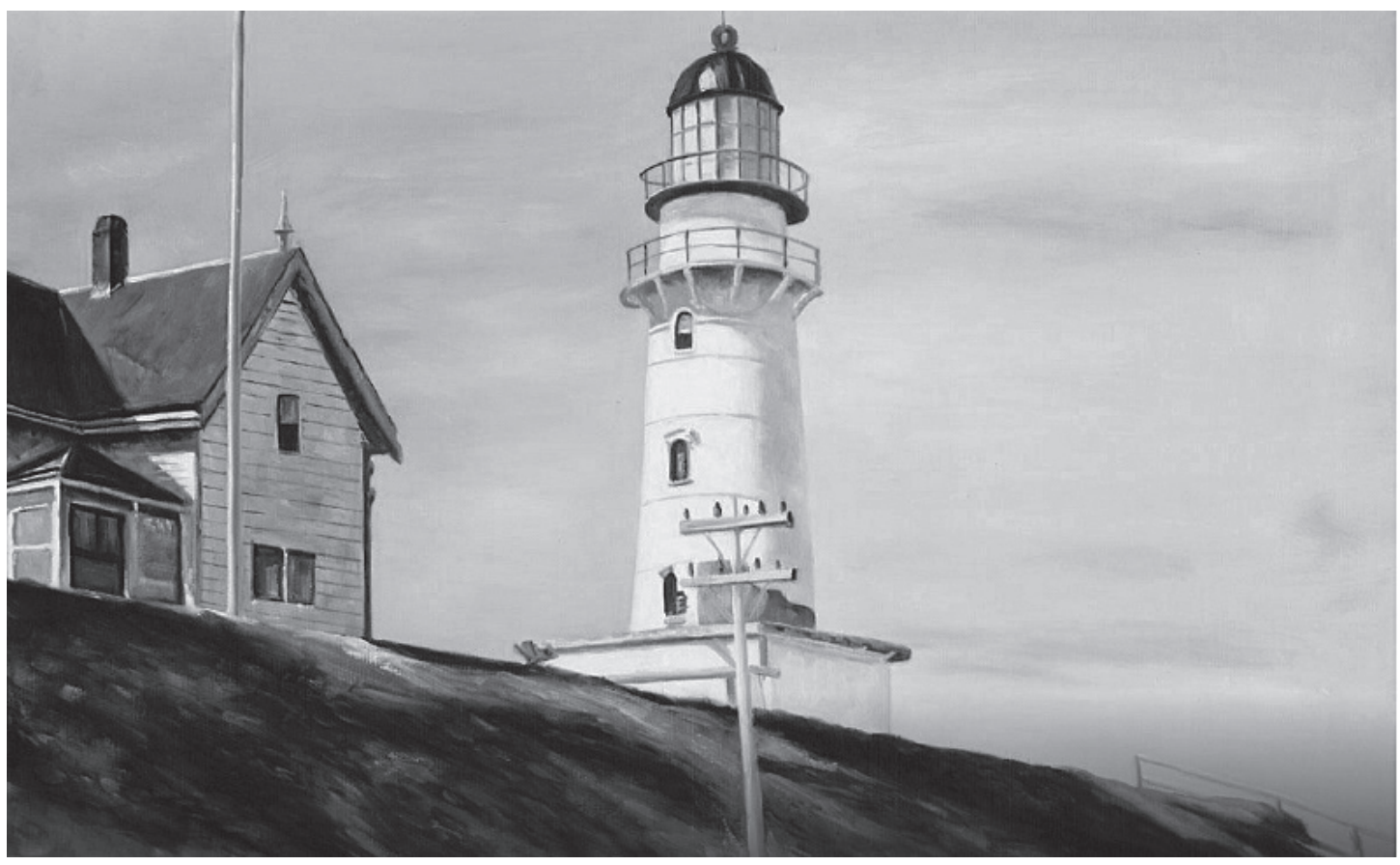

Fig. 4 Light at Two Lights (1927) de Edward Hopper. Acuarela y grafito sobre papel. Obra localizada en el Whitney Museum of American Art de Nueva York.

les lumínicas, su majestuosidad y su verticalidad -casi sacras-, o la soledad y el misterio inherentes a las escenografías en las los faros se ubican. La dedicación y el interés constante de este artista por la temática farera, cuyas obras se mueven entre el realismo fotográfico y el naturalismo vanguardista, ha terminado por trascender la propia creación pictórica, convirtiéndole en un verdadero experto coleccionista:

"El faro, que siempre ha tenido un gran atractivo emblemático por su noble arquitectura, el lugar donde está situado, el misterio de la noche, etc., no podía quedar fuera de la sensibilidad artística, por lo que a través de todos los tiempos y de la Historia del Arte ha sido muy bien tratado. Desde los primeros grabados, mosaicos, monedas y dibujos, imaginarios con la representación tanto del Faro de Alejandría como del Coloso de Rodas, hasta el día de hoy, centenares de artistas han incorporado este motivo tan singular en algunas de sus obras. Desde el Bosco con El Jardín de las Delicias y Brueghel con El Triunfo de la Muerte, donde ya aparecen las torres con fuego de las hogueras, podemos citar a Claudio de Lorena, muchos de los impresionistas como Monet, Signac, Seurat, Bodin, etc., románticos como Böeklin, Turner, los Bonnar, Matisse, Picasso, Balthus,
Hopper, hasta el conceptualista Beuys con su Faro de Sebastopol, 1946. Aunque aceptemos lo heterogéneo del tema y sus múltiples variantes e interpretaciones y los excelentes cuadros de los distintos pintores, me atrevería a decir que Edward Hopper sería el número uno, el maestro. Esto es solamente llamar la atención sobre algún artista. Tengo material y nombres para escribir un libro que casi sería una guía telefónica”25.

No obstante, el artista santanderino no es el único autor de ilustraciones y textos que, tomando los faros del litoral español como protagonistas, compila dicha información en forma de publicación especializada. A tal efecto, contamos con aportaciones análogas como Faros de Guipuzkoa (2002), una obra ilustrada por Jokin Leniz Aranbarri y con textos de Paloma de Roda Lamsfus que analiza el faro de Higuer, el de la Plata, el de Senokozulua, el de Santa Clara, el de Igueldo, el de Guetaria y el de $\mathrm{Zu}$ maia así como trata referencias a los ingenieros y arquitectos Joaquín Arguedas, Carlos Campuzano, Manuel Estibaus, Francisco Lafarga, Alberto Machimbarrena, Manuel Peironcely y Julián Sánchez Bott, artífices que definieron y

25 Calvo Serraller, Francisco, Sanz, Eduardo y Sazatornil Ruzz, Luis, op. cit., Centro de Arte ..., p. 179. 


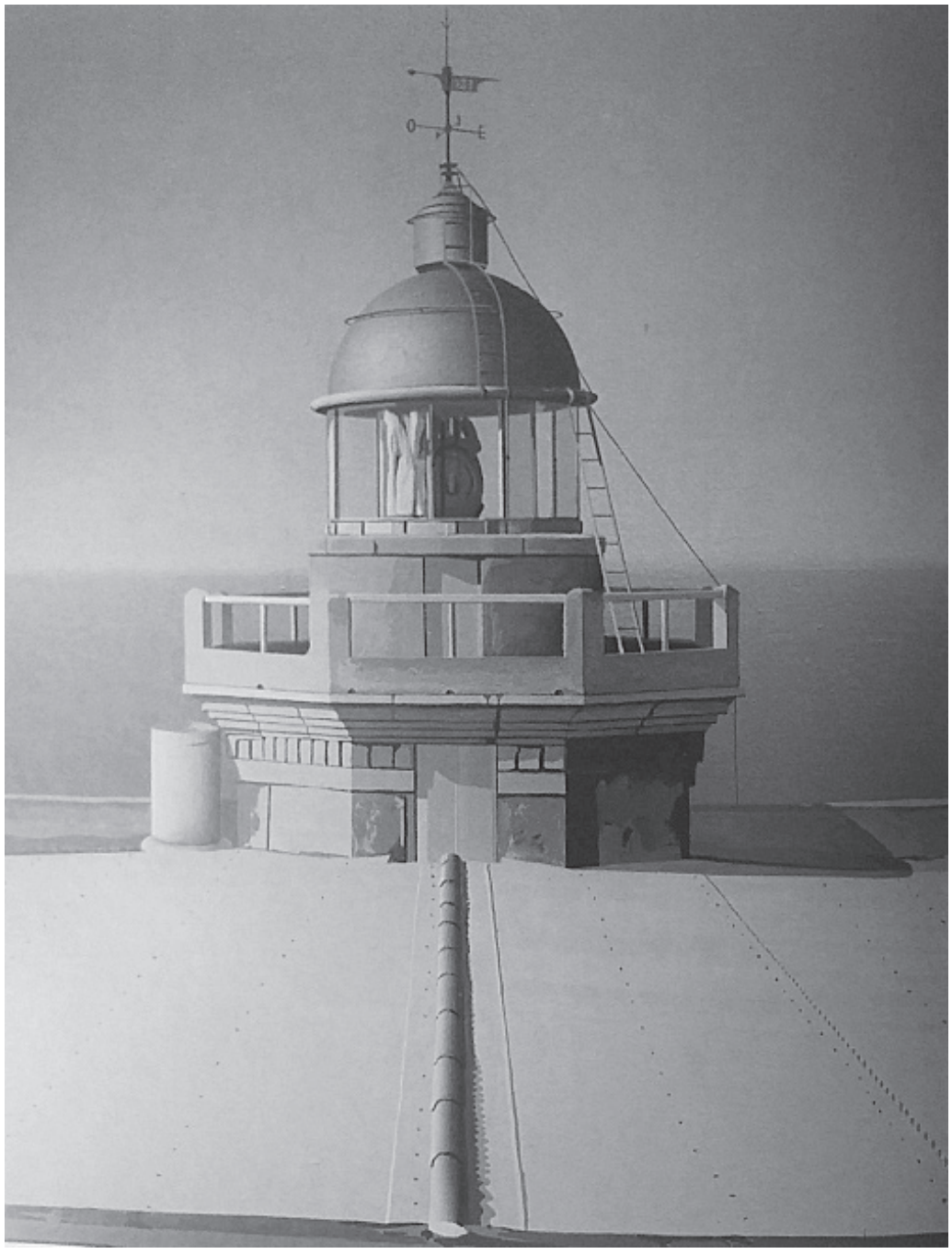

Fig. 5 Linterna del Faro de Torres (1980) de Eduardo Sanz. Acrílico sobre lienzo. Obra no localizada.

consolidaron a lo largo del siglo XIX la iconografía farera dispuesta desde el monte Jaizkibel hasta Zumaia ${ }^{26}$.

Volviendo a la línea apuntada por Eduardo Sanz y a esa serie de referencias artísticas ineludibles, insistiremos en algunos autores $u$ obras que terminarían por completar esta sucinta referencia al imaginario del faro en la Historia del Arte. Tal es el caso de las vistas del Faro de Wetskapelle o Wistkapelle de Piet Mondrian (1872-1944), realizadas hacia 1910 para representar una de las estructuras fareras con las que cuenta la localidad homónima ubicada en el área suroccidental de los Países Bajos. Se conservan varias obras que recogen este motivo planteado desde distintas coordenadas artísticas, pasando de un lenguaje pos-

26 De Roda Lamsfus, Patricia, Faros de Guipuzkoa, Editorial Scriptum, Madrid, 2002. timpresionista, que hace uso de una técnica puntillista, a otro de raigambre expresionista que pone de relieve el potencial comunicativo del color. Asimismo, en algunas de las imágenes la arquitectura propuesta se desmaterializa progresivamente mediante un lenguaje que, en su sencillez formal y su esencialidad geométrica, parece evocar más al minarete de una mezquita -una de ellas recuerda a la Koutoubia de Marrakech- que a un faro ${ }^{27}$. Por el contrario,

$27 \quad$ Este parecido responde a partes iguales a cuestiones de distinta índole: la primera es de tipo compositivo y se relaciona con el encuadre elegido para la imagen, ya que el artista decide representar este faro casi a sus pies, adoptando un ángulo marcadamente contrapicado que sólo permite ver el cuerpo de la estructura, ocultando su remate; la segunda y principal razón de esta similitud tiene que ver con la naturaleza de propio faro alto de la ciudad de Westkapelle, localidad que dispone de dos faros activos, ya que fue erigido en 1818 sobre la torre reaprovechada de una iglesia que 
en otras ocasiones el faro de Wetskapelle llega a desdibujarse completamente, disolviéndose en el espacio y resultando difícilmente reconocible. También sobresale la serie de faros pintada por Edward Hopper (1882-1967) entre las décadas de 1910 y 1930, si bien la mayoría de las obras fueron realizadas entre los años de 1927 y 1930. Los paisajes fareros que Hopper recoge se sitúan a largo de la costa Este de los Estados Unidos, aunque el artista atiende especialmente a los que se localizan en el estado de Maine, tal y como reflejan las obras Lighthouse Hill (1927), Lighthouse and building, Portland Head (1927), Lighthouse Hill, Cape Elizabeth, Maine (1927), Captain Upton's House (1927), Pemaquid Point (1929) y Light at Two Lights (1927). En estas imágenes se encuentra impreso el sello artístico de Edward Hopper, advertido en la presentación de los faros y de sus entornos paisajísticos mediante un lenguaje realista que, con concesiones a un brillante tratamiento lumínico y cierta saturación cromática, consigue unir la estética de la cotidianeidad y una fuerte carga poética.

De igual modo existen otro tipo de representaciones en donde el paisaje se mezcla con la presencia humana, siendo el caso de Recuerdo de Hamburgo (ha. 1921) de Otto Dix, una obra que roza el formato de la postal estival recogiendo, con un sentido alegórico y jocoso, buena parte de los clichés que caracterizan el universo portuario y marinero. Así, la obra nos ofrece una serie de micro-imágenes del faro, el mar, la embarcación, una playa llena de conchas y crustáceos y dos figuras arquetípicas en la galería de los perfiles humanos asociados al medio marítimo-portuario, como son el marinero y la prostituta. No obstante, también contamos con otras obras cuyas referencias figurativas responden a voluntades bien distintas. Aquí podríamos citar Le Chat de la Méditerranée (1940) de Balthus, donde una mujer joven y un gato humanizado, personajes altamente característicos de la enigmática obra de este artista polaco-francés, aparecen junto a un paisaje marítimo y un espigón, en cuya punta se aprecia un faro, cerrando la composición.

ardió en el siglo XVIII. Para más información véase Termeulen, Thomas, Topografische Atlas Zeeland, editorial Uitgeverij 12 Provincien, Landsmeer, 2015.
Para finalizar este recorrido terminaremos por tratar algunas características de la geografía farera asturiana así como parte de las obras que se la recogen. Como tantas otras veces, la región asturiana dispuso tardíamente de su primer faro moderno, ya que no fue hasta 1852 cuando comenzó a edificarse el faro de Cabo de Torres. Sin embargo, se conocen precedentes de funcionalidad análoga al tratarse de recursos destinados a la guía de las embarcaciones. Como en otros contextos geográficos, nuestra costa contó con fuegos nocturnos dispuestos en puntos elevados para que los navegantes pudiesen orientarse así como saber si era posible atracar en el puerto al que pretendian dirigirse. Además, los lugares donde ardian estas hogueras eran tenidos por sacros debido a la protección que ofrecían ante la temida deriva, terminando por construirse ermitas en muchos de los enclaves donde antes se disponían las pequeñas torres contenedoras de estos fuegos ${ }^{28}$.

Reside aquí el origen de la construcción que se representa en Dos vistas de Luarca desde la ermita, hacia el E y el W (1985) de Eduardo Sanz, donde se traduce el paisaje litoral que se contempla desde la ermita de la Virgen Blanca en Luarca, una zona que aún a día de hoy conserva las fábulas que surgieron en torno a su importancia como referente en la navegación nocturna. El artista candasín Antonio Rodríguez, Antón (1911-1937) también hizo lo propio en algunas de sus obras, en las que podemos advertir el gusto por las capillas populares como la del Carmen en Luanco (Capilla del Carmen, Luanco, ca. 1935) y las ermitas de San Antonio y de San Roque (Vistas de San Antonio, 1935). Algunas de estas construcciones habían sido erigidas como exvotos populares tras el padecimiento de oleadas de peste pero también se localizaban donde antaño habían sido encendidos esos fuegos o "teas" 29 por los

28 Estas ermitas eran construidas por los propios marineros y pescadores de la zona con una doble intención: definir un espacio eclesiástico que procurase ayuda o asistencia espiritual pero que también pudiese albergar una señal lumínica que hiciese las veces de guía física. Es por esta razón que dichas ermitas o capillas siempre disponían de una luz nocturna. Rodríguez GonzÁLEz, Armando, "Los faros de Asturias", en Asturias y la Mar, Editorial Prensa Asturiana y Ediciones Nobel, Oviedo, 2006, pp. 427-448.

29 La voz "tea" suele emplearse en prensa asociada a usos relacionados con las señales lumínicas procedentes del fuego. No obstante, también son comunes 
atalayeros o encargados de mantener viva la llama durante la noche ${ }^{30}$.

El uso de estas hogueras llegó a coexistir con la utilización de candelas y de lámparas que eran alimentadas por diferentes combustibles desde la segunda mitad del siglo XVIII, permitiendo dirigir con cierta efectividad los haces de luz en estos ejercicios de señalización, evolucionando progresivamente y experimentando diversas mejoras en su perfeccionamiento. Este camino terminó derivando en los diversos ingenios mecánicos que protagonizaron las máquinas de rotación, unos sistemas que operaban sobre unas maquinarias de relojería y que permitían emitir destellos de luz a intervalos fijos mediante un particular sistema óptico. Finalmente, el desarrollo progresivo de la ciencia farera desembocó en la aparición de la tipología del faro eléctrico, una innovación capital que permitió que el faro funcionase automatizadamente y sin necesidad de una persona que lo manejase ${ }^{31}$.

aquellos que, insistiendo en las nociones de fuego y luz, se vinculan a hechos o versos marianos. A tal efecto, se cita un ejemplo: “(...) hiere a la Virgen y su altar saquea sin que apaguen el fuego de su tea, las lágrimas de amor con que Ella llora”. Revista semanal Acción: defensor de los intereses de la mujer, Gijón, 6-VIII-1932.

30 Subrayaremos el caso de la ermita de San Roque en Candás puesto que el monte sobre el que se localiza, el de San Sebastián, es más conocido por el sobrenombre de monte Fuxa debido al atalayero que allí se situaba. Francisco Muñiz "Fuxa" fue contratado en 1890 por la Sociedad de Mareantes de Candás para encargarse, entre los meses de enero y febrero, del fuego de señalización que permitía a los marineros volver tras las jornadas de la costera del besugo. Para ello se sabe que este atalayero empleaba varios fuegos con la intención de advertir la posible entrada y fondeo en el muelle mediante un sistema cifrado de la manipulación lumínica. Así el empleo de dos fuegos traducía la presencia de una galerna y el de tres la imposibilidad para atracar en el puerto por el estado de la mar. Este famoso atalayero también llegó a inspirar una canción popular. Rodríguez GonzÁlez, Armando, "Los faros de Asturias", op. cit., p. 429.

31 El proceso de automatización de los faros en nuestros tiempos ha motivado la extinción de la figura del farero. Este trabajo solía desarrollarse a través de dos modalidades, bien mediante una plantilla de trabajo colectiva, bien gracias a una única persona encargada de su funcionamiento. El primer caso era particularmente común en las dinámicas de aquellos faros que se encontraban alejados de la costa, por lo que estos trabajadores pasaban largas temporadas alejados de sus familias y rotaban su trabajo en función de unas tres o cuatro personas que trabajaban por turnos, contando siempre con la presencia de un guardia fijo. Sin embargo, el segundo caso solía corresponderse
Actualmente, la gestión y el funcionamiento de los faros asturianos recaen sobre las $\mathrm{Au}$ toridades Portuarias de Gijón y de Avilés, encargándose la Autoridad Portuaria de Gijón (APG) del control de las señales marítimas de la mitad regional oriental mientras que la $\mathrm{Au}-$ toridad Portuaria de Avilés (APA) lo hace con las de la mitad occidental. Aunque casi todos estos faros se encuentran representados en las distintas imágenes disponibles, cuyo número es considerable, han sido realizadas mediante distintas técnicas, proceden de diversos autores y su cronología se extiende desde el siglo XIX hasta nuestros días, hemos de escoger un conjunto reseñable y sintomático para poder cerrar este artículo. En este sentido, volveremos de nuevo a Eduardo Sanz, autor de buena parte de las vistas de los faros de nuestra región así como de otras imágenes costeras que plasman sus entornos, paisajes así como otro tipo de señales marítimas. Todas estas obras aparecen compiladas en la publicación Faros de Asturias (1990), un libro que vio la luz gracias al trabajo de este artista y a la iniciativa y mediación del editor gijonés Silverio Cañada Acebal (19322002). Al respecto, artista y editor acordaron la elaboración de una serie de pinturas, dibujos e ilustraciones que, acompañados de textos que recuerdan a un cuaderno de bitácora, plasmarían diversa información visual y textual. De la misma forma, las expediciones y las actividades realizadas al socaire del trabajo de campo desempeñado quedan registradas en las notas que el artista tomó, permitiendo al lector recrear esta aventura artística y sumergirse en estas vivencias ajenas.

al desempeño de un único guarda que vivía con su familia en el propio faro, responsabilizándose de su actividad sin disponer de nadie que le relevase. Salvo excepciones, los fareros solían ser hombres que previamente habían trabajado como marineros y pescadores, disponiendo de una trayectoria profesional que les convertía en expertos de la mar, un requisito fundamental para poder prever y leer el comportamiento del medio así como prestar atención al correcto desarrollo de todas sus funciones. Sus obligaciones implicaban diversas labores de mantenimiento y reparación como cambiar periódicamente el aceite de las lámparas, revisar y reparar engranajes, mecanismos y piezas, encargarlas y sustituirlas en caso de rotura o accidente, limpiar y mantener las lentes, coordinar las distintas señales lumínicas y, en caso de que el faro dispusiese de esta herramienta, hacer sonar la señal que guiaba audiblemente las embarcaciones en situaciones de niebla. Rodríguez GonzÁlez, Armando, "Los faros de Asturias", op. cit. 